\title{
Multi-Touch Technology and Preschoolers' Development of Number-Sense
}

\author{
Anna Baccaglini-Frank ${ }^{1} \cdot{\text { Mirko } \text { Maracci }^{2}}^{2}$
}

Published online: 28 April 2015

(C) Springer International Publishing 2015

\begin{abstract}
The technology-enhanced development of very young children's mathematical abilities, apart from some notable exceptions, does not seem to have yet raised a lot of interest within the mathematics education community. This article focuses on the educational potential offered by certain software applications (apps) that exploit affordances of multi-touch devices for fostering preschoolers' development of number-sense. We introduce theoretical elements derived from recent research in developmental and cognitive psychology, neuroscience, and mathematics education, that concur in defining the aspects of number sense that we will be investigating in relation to specific multi-touch interactions. Our specific research goal is to analyze the multi-touch potential of two apps for fostering preschoolers' development of those aspects of number sense. The study is based on the analysis of children's interactions with these apps in the context of a sequence of activities centered on the use of the iPad, carried out in a public preschool in Northern Italy. The specific issue addressed and the perspective adopted position this study at the crossroads between different research fields.
\end{abstract}

Keywords Multi-touch technology $\cdot$ Number sense $\cdot$ Representation of quantities through fingers $\cdot$ iPad applications $\cdot$ Preschoolers' stable schemes

\section{Introduction and Rationale}

Recent advances in the fields of technology and computer science have opened a great number of possibilities in terms of the types of interactions that users can have with the various available devices. In particular, the mouse and keyboard, once essential interfaces, are no longer necessary for interacting with software: the advent of

Anna Baccaglini-Frank

abaccaglinifrank@gmail.com

1 Department of Education and Human Sciences, University of Modena and Reggio-Emilia, Reggio Emilia, Italy

2 Department of Mathematics, University of Pavia, Pavia, Italy 
interactive whiteboards, touch tables, tablets, and smartphones has offered the possibility of acting directly on screens through pens or simply fingers. These devices recognize as different inputs a variety of single-finger and multi-finger touch gestures as well as voice inputs (when speech recognition software is installed). Of course these new possibilities for software can, and may we add, should, have implications for educators, be they teachers, parents, researchers, or software designers.

In this article we focus on the educational potential offered by certain software applications (apps) that exploit multi-touch affordances for fostering preschoolers' (age 4-5) development of number-sense.

Tablets, and in particular iPads, have appropriate dimensions for fostering young children's touch-interactions, and there is a great variety of apps developed for such technologies' operating systems. However, most of these apps are presented in the form of games or quizzes, proposed as closed interactions, mostly designed for repeating number facts, and that only support input from a single-finger touch, as if it were the old fashioned mouse click, drag, or single taps on the keyboard. In general, input is expected as a choice among possible "answers", or as a "typing in" of the answer (the finger is used to tap on virtual keys). So typical apps of this nature do not take advantage of many of the new opportunities offered by multi-touch technology, and in particular by the affordance of recognizing a variety of touch gestures, possibly executed simultaneously. There are notable exceptions, such as software developed by Sinclair and Jackiw (2011) or by Ladel and Kortenkamp (2009, 2011) that propose mostly open-ended interactions with virtual manipulatives, and some other apps that, even offering only closed conversing-type interactions (Sedig and Sumner 2006), are designed to foster children's perception of numerosity ${ }^{1}$ (from 1 to 10) and of particular ways of using fingers to represent such numerosities (Sinclair and Baccaglini-Frank 2015). We will focus on the experiences of a group of preschool children in contexts of this second type.

Since we are interested in analyzing particular types of multi-touch interactions with respect to aspects of number-sense that they may foster, two important problems that we need to address are: 1) what this type of knowledge for very young children can look like, and 2) how it can be "observed". Once we will have proposed a theoretical background that addresses these issues, we will be able to discuss what exploiting the potential offered by multi-touch technology for developing number-sense in young children might mean, and we will be able to analyze under this light findings that emerged from the experiences we offered the preschoolers in our study.

\section{Conceptual Framework}

While extensively studied in cognitive psychology, the development of very young children's mathematical abilities seems not to have raised a lot of interest within the mathematics education community (some notable exceptions are Clements and Sarama 2007; Sinclair and Moss 2012; English and Mulligan 2013; Perry and Dockett 2013).

\footnotetext{
1 "Numerosity" is taken from the literature in cognitive psychology and neuroscience; it is used in the context of perceiving, elaborating or representing the quantity of a set of objects.
} 
We think that one reason could be related to the difficulties in attesting the emergence of mathematical knowledge when very young children (pre-kindergarten, ages 3-5) are involved. In fact, when addressing the issue of preschool children's development of mathematical abilities, one of the challenges is to accordingly reconceive mathematical knowledge itself.

\section{Number-Sense: An Elusive Notion}

The notion of number-sense can be considered a "boundary object" (Cobb et al. 2003; Star and Griesemer 1989), in the sense that it is at once a "common-sense" notion and a yet-emergent notion in cognitive science and in mathematics education. Being at the intersection of different fields, boundary objects have the potential of serving as vehicles to communicate and convey meaning across different communities, even if different communities can define and interpret them in different ways.

In this respect, there is no monolithic interpretation of the notion of number-sense across the communities of cognitive scientists and of mathematics educators, and not even within the community of mathematics educators alone. This is well depicted, for example, by Berch's words (2005): "number sense reputedly constitutes an awareness, intuition, recognition, knowledge, skill, ability, desire, feel, expectation, process, conceptual structure, or mental number line" (ibid. p. 333).

Despite this heterogeneity, there seems to be a certain consensus about some features of the notion of number-sense which have important implications for mathematics education.

The development of number-sense is seen as a necessary condition for learning formal arithmetic at the early elementary level (Griffin et al. 1994; Sowder 1992; Slavit 1998; NCTM 2000) and it is critical to early algebraic reasoning, in particular when it is considered at the heart of perceiving the "structure" of number (Mulligan and Mitchelmore 2013).

In particular, literature from the fields of neuroscience, developmental psychology, and mathematics education indicate that using fingers for counting and representing numbers (Brissiaud 1992; Ladel and Kortenkamp 2011), but also in more basic ways (Butterworth 1999, 2005; Noël 2005; Gracia-Bafalluy and Noël 2008), can have a positive effect on the development of numerical abilities and of number-sense. It is agreed upon across fields that both formal and informal instruction can enhance number-sense development prior to entering school.

We will consider number-sense according to the broader meanings advanced for the construct within the field of mathematics education, and we will accept its being based on certain "component abilities", as has been hypothesized in cognitive psychology. In the following paragraphs we introduce theoretical components that concur in defining the aspects of number sense that we will be investigating in relation to specific multitouch interactions.

\section{Fingers and the Development of Numerical Abilities}

Research in neuroscience has shown that there is a neurofunctional link between fingers and number processing. For example, Butterworth $(1999,2005)$ has hypothesized that numerical representations and processes are supported by several component abilities: 
the innate ability to recognize small numerosities without counting (subitizing), fine motor ability (for example, finger tapping), and the ability to mentally represent one's fingers (finger gnosia). According to this hypothesis, it is through our fingers that we construct concrete and abstract representations of number, number words, and number symbols. He states explicitly that:

"Without the ability to attach number representations to the neural representations of fingers and hands in their normal locations, the numbers themselves will never have a normal representation in the brain." (Butterworth 1999, pp. 249-250).

Such hypothesis is supported by later research. In a study by Penner-Wilger and colleagues, (Penner-Wilger et al. 2007) each component ability was found to be a significant unique predictor of number system knowledge, which in turn was related to calculation skill.

Noël has also obtained results that support such hypothesis (2005), and, with GraciaBafalluy, she has in addition demonstrated, how consistent use of fingers positively affects the formation of number-sense and thus also the development of calculation skills (Gracia-Bafalluy and Noël 2008).

Other researchers have suggested that finger-based counting may facilitate the establishment of number practices (Andres et al. 2007; Sato et al. 2007; Thompson et al. 2004; Domahs et al. 2012; Lafay et al. 2013).

From an educational point of view, literature has recognized five principles as necessary for children to master for developing number-sense (Gelman and Gallistel 1978); these are a) the one-one-principle that relates every single object to exactly one numeral; b) the stable-order principle prescribing the correct order of numbers; c) the last-word rule that assigns the last said numeral not to the last counted object, but to the quantity as a whole; d) the principle of abstraction, according to which objects of any nature, also abstract, can be counted; e) and the order in which the objects are counted does not matter.

We believe that through the use of fingers for dealing with quantities children can start developing the needed mastery of these principles. Comparing the quantities of two collections of objects or representing a certain quantity with fingers can be done without using numbers directly, but by establishing one-to-one correspondences between objects or between objects and fingers. Margolinas and Wosniak (2012) stress the importance for developing number sense of considering quantities independently of numbers. These processes are intertwined with development of the so-called "finger symbol sets" (Brissiaud 1992) that is the representation of numbers and numbers operations and relations through finger gestures.

Such form of representation of quantities by some children can be established early and in parallel to the development of the mental number line - another fundamental representation of number that is developed through exposure to number (Dehaene 2001; Zorzi et al. 2002), in Western cultures (see, for ex., Nunez 2011) - as an autonomous type of numerical representation. Finger strategies may foster the learning of the decompositions of all numbers up to 10 in a way that can be utilized for addition and subtraction. Learning decompositions (especially of 5 and 10) in this way allows the child to develop a nonverbal-symbolic representation of the fact that "two parts make a whole", that is the complementarity of two numbers with respect to a given 
number. This is the foundation of what Resnick et al. (1991) coined as the part-whole concept. Part-whole knowledge also seems to be important for becoming aware of structure in numbers (Mulligan 2011; Mulligan and Mitchelmore 2013) and for early arithmetic problem solving, and it can be developed as early as 4 to 5 years of age (Sophian and McCorgray 2009).

\section{Embodied Cognition and the Notion of Body Syntonicity}

The importance of the role attributed to the use of fingers in the development of number-sense by the quoted literature is highly resonant with the frame of embodied cognition developed by Gallese and Lakoff (2005), which has a growing influence in mathematics education research (Arzarello et al. 2007; Nemirovsky 2003; de Freitas and Sinclair 2013; Radford 2014). Within this perspective doing, touching, moving and seeing are essential components of mathematical thinking processes - from the initial phases of the conceptual development to the most advanced learning processes. Radford et al. (2005), for example, write: "sensorimotor activity is not merely a stage of development that fades away in more advanced stages, but rather is thoroughly present in thinking and conceptualizing." (ibid., p 114).

We find hypotheses like that of Butterworth, highlighting the necessity of linking the representation of numbers to the neural representations of fingers, to be completely in line with the embodied cognition approach. Moreover, we believe that such approach overcomes some of the rigid boundaries across confining disciplines such as cognitive psychology and mathematics education, in our case.

When considering the use of digital artefacts - and specifically of microworlds - in mathematics education, this approach reminds us of the notions of body and ego syntonicity originally developed by Papert (1980). According to these notions, the potential of microworlds relies on the possibility for children to relate the behavior of the microworld objects with their sense and knowledge about their own bodies (body syntonicity), and to attribute intentions to these objects in ways coherent with their own intentions, goals and desires (ego syntonicity) (Healy and Kynigos 2009).

\section{The Notion of Scheme}

The perspective depicted so-far while putting forwards the importance of the role of the individuals' bodily actions in conceptualization, risks leaving in the shadow the link between these actions and the individual's goals and intentions in a given situation, and certain characteristics of the situation itself. We think that the notion of scheme as developed by Vergnaud $(1990,2009)$ helps to frame all these components coherently.

Elaborating on the Piagetian notion of "scheme", Vergnaud characterizes it as an invariant organization of the activity for a given class of situations. ${ }^{2}$ More precisely, a scheme comprises: expectations of the goals and effects which can be achieved through action in given situations, rules of action that allow generating a sequence of actions to achieve the anticipated goals in given situations, operational invariants, and inferences

\footnotetext{
${ }^{2}$ We use the term situation after Vergnaud (1990, p.151): «toute situation peut être ramenée à une combinaison de relation de base avec des données connues et des inconnues, lesquelles correspondent à autant de questions possibles.».
} 
that allow to derive the expectations from the information and the system of operational invariants available for the subject.

Even though all the components of a scheme are important, operational invariants have a prominent role. They consist of the implicit knowledge which structures the whole scheme: they drive the identification of the situation and of its relevant aspects, and allow selecting suitable goals and inferring the rules for generating appropriate sequences of actions for achieving those goals.

We do not wish to enter a debate on the fundamental core assumptions underlying embodied cognition on the one hand and Vergnaud's theory of knowledge and conceptual development on the other hand, and on their compatibility. However we are aware that the notion of scheme might be seen as being in opposition to the embodied cognition approach, if the former notion is assumed to suggest the "existence of a mind" behind the perceptuo-motor activity, or the idea that "perceptuo-motor activity functions as input and output for the 'mental' realm" (Nemirovsky and Ferrara 2009, p.161; Healy and Kynigos 2009). We note that other colleagues have insightfully combined notions of Vergnaud's theory with an embodied cognition perspective into their own research (Abrahamson \& Howison 2010; Arzarello et al. 2007; Charoenying et al. 2012). We, too, believe that the two perspectives provide useful analytical tools which can be combined to describe crucial cognitive aspects of students' interactions with digital artifacts.

\section{Research Questions}

Given the theoretical components we have introduced, and certain methodological constraints we will describe in Methodology section, we chose particular aspects of number-sense with respect to which we advanced the following working hypothesis:

Multi-touch technology has the potential to foster important aspects of children's development of number-sense, including the ability to use fingers to represent numbers in an analogical format. We will call this the multi-touch potential.

The "aspects of number-sense" that we took into consideration in our analyses include component abilities, as suggested by the cognitive psychology and neuroscience literature, some of the counting principles and recognizing parts of a whole (possibly without subitizing), suggested within the mathematics education literature; and the ability to match numbers of fingers (not instantaneously) to a number of objects, without counting. Although not very advanced from a mathematical point of view, this ability seems to be an important stepping stone for quickly representing numbers with fingers. Table 1 shows the specific sub-aspects of the main categories listed above.

Our specific research goal was to analyze the multi-touch potential of two apps for fostering preschoolers' development of number-sense, by

- investigating the schemes that children develop in their interactions with the software, and in particular how they use their fingers;

- attempting to relate the schemes enacted to the development of number-sense. 
Table 1 Aspects of number-sense we took into consideration for investigating the multitouch potential of some apps

\begin{tabular}{lll}
\hline Aspects of number sense & Multiple fingers tapping & Simultaneous \\
& Sequential & Simple \\
Subitizing & Double subitizing \\
Recognizing parts of a whole & \\
One-to-one correspondence & \\
Approximate estimation & Small quantities (1-5) \\
& Large quantities (5-10) \\
Counting principles & - One-one \\
& - Stable order \\
& - Cardinality \\
& - Order-irrelevance \\
\hline
\end{tabular}

\section{Methodology}

The study is based on the results of a sequence of activities centered on the use of different apps ${ }^{3}$ for the iPad, carried out in a public preschool in Northern Italy over a time period of 2 weeks.

The sequence was enacted by a pre-service preschool teacher - an undergraduate student of Department of Education at the University of Modena and Reggio Emilia - as part of her mandatory internship. Hence the design of the sequence of activities had to fulfill a number of constraints imposed by the training agreement between the Department of Education and the hosting school, that concerned the amount of time devoted to the activities with technologies, the organization of the activities over time, the number of iPads available, the amount of time for children to use the iPads and the kind of activities they could accomplish, and the choice of the apps. More specifically we could use only already published, free or very cheap apps, easy for children to become familiar with, and presenting a strongly structured environment allowing primarily closed conversing-type interactions (Sedig and Sumner 2006; Sinclair and BaccagliniFrank 2015). The apps used in the study were chosen and built into the activities protocol by the first author; they will be described in Description of the Apps Used section.

On the one hand such constraints can appear as strongly limiting factors for a research study; on the other hand they represent typical features present in Italian pre-schools when new activities are proposed either by the regular teachers or by preservice teachers that have permission to enter the classrooms. Since an underlying aim of this study was to impact on mathematics teaching practice, we chose to respect and incorporate such constraints.

The sequence of activities was carried out in a class of 25 children, between the ages of 4 and 5 ( 6 of them were foreign children who did not speak Italian). The children were introduced to the 3 apps during 2 initial free-play sessions $(2 \mathrm{~h})$; then for 2 weeks, every day, they had sessions of about $25 \mathrm{~min}$, working in groups of 5 children at a time with an iPad per group. Therefore each child spent a total of about 50 min interacting

\footnotetext{
${ }^{3}$ The study involved the use of three apps, but we will be analyzing results obtained from two of them.
} 
directly with the apps. When not interacting with the apps the children watched their classmates work, and, if prompted by the pre-service teacher, helped them through verbal or gestural utterances.

The pre-service teacher attended all the group sessions, but intervened only to call each child within the group when it was his/her turn to interact with the iPad; to draw the children's attention to their classmate's work with the iPad, or to ask them to help their classmate. The pre-service teacher was accompanied by a second student of the Department of Education who video-recorded the children's interactions with the iPad.

\section{Video Analysis}

The analysis of schemes enacted by the children when interacting with the apps raises the crucial methodological issue of how schemes can be inferred from observation.

In this respect, the leading idea is to look for regularities in the children's behaviors across a number of situations. Bourmaud (2006, p.41), after Zanarelli (2003), stresses the need of investigating the following dimensions of the activity: the regularities of the sequences of subject's actions, the existence of possible different choices for the subject's actions, the effects of the actions on the situation at stake and their efficiency. At the same time, he points out that even if the schemes can be inferred by the observation of the activity, they are difficult to verbalize. This is consistent with Lagrange's remark: "being adaptive mental constructs, schemes cannot be entirely described in a rational form" (1999, p.58). Also for this reason, the current state of development of our research suggests us to be cautious with respect to the possibility of describing children's schemes, and the conclusions that can be drawn from our analyses.

The analysis of the videos was, therefore, aimed at identifying and describing the situations which the children faced when interacting with the apps, and the stable recurring strategies which children enacted in those situations, that is the possible "regularities" in the children's behavior evoked above.

Coming back to the idea of scheme, stable recurring strategies could be related, to some extent, to the operational invariants. The description of the operational invariants is of crucial importance in the analysis of schemes, in fact it is the concept of operational invariant which allows to capture the essence of the scheme: «c'est le concept d'invariant opératoire qui permet de faire le lien entre la forme opératoire et la forme predicative de la connaissance, justement parce qu'il s'agit de la composante épistemique du schème, celle qui soutient en dernier ressort l'organisation de l'activité»» (Vergnaud 2005, p.129).

\section{Description of the Apps Used}

We have mentioned previously that the design of the sequence of the activity for this study had to fulfill several constraints, influencing also the choice of the apps.

In fact, due to those, we could not propose the use of some very interesting apps which exploit the potential of multi-touch screens in innovative ways, offering openended environments that allow a wide range of possible interactions (Sinclair and 
Baccaglini-Frank 2015). For example, the app TouchCounts, developed by Sinclair and Jackiw (2011), offers the possibility to create quantities and interact with them, through manipulative interactions (Sedig and Sumner 2006) and encourages the user to associate specific gestures to numerical manipulation, thus promoting children's meaningmaking (Goldin-Meadow 2004).

Within our constraints, we identified two apps which seemed to have some potential for fostering the development of children's number-sense, addressing some the aspects of number-sense with respect to which we set out to investigate the software's potential. They are: Ladybug Count ${ }^{4}$ and Fingu. ${ }^{5}$

\section{Ladybug Count (Finger Mode)}

The following description refers to the "finger mode" of the environment.

The layout of this app is the top view of a ladybug sitting on a leaf, and the aim of each playing turn is to make the ladybug walk off the leaf. This happens when the child places on the screen (in any position) as many fingers as the dots that are on the ladybug's back. Given a certain number, the dots appear on the ladybug's back always in the same pattern. As each finger is placed on the screen one of the dots on the ladybug's back is highlighted (Fig. 1), and the iPad makes a "pop" sound. When all the dots are highlighted there is a feedback sound which precedes the announcement of the number of dots that were on the ladybug's back. At this time the ladybug walks off the screen and a new one appears. This process repeats as long as the child wants to play.

If the child places more fingers on the screen than the dots on the ladybug's back, all the dots become highlighted, but the ladybug does not walk off the leaf and a voice says: "Oops!". If the child places on the screen fewer fingers than the dots on the ladybug's back, only a number of dots corresponding to the fingers on the screen is highlighted and nothing else happens. This app will be referred to as LBC.

\section{Fingu}

The layout of this environment (Barendregt et al. 2012) looks like a room in which different kinds of floating fruits appear. The objects appear in one group or in two groups that float independently, but within each group the arrangement of the objects remains unvaried. The child has to place on the screen, simultaneously, as many fingers as the objects that are floating within a given amount of time (Fig. 2a and b).

If $\mathrm{s} /$ he succeeds $\mathrm{s} /$ he receives a positive feedback from the system consisting in an auditory signal and few dancing happy animations. Otherwise, if the number of fingers is incorrect or time elapses, a negative feedback is given through a different auditory signal and the appearance of sad animations. Then the child can play the next round, until s/he looses or passes the level. The game provides statistics on the performance of the child for each level attempted. This app will be referred to as $\mathrm{F}$.

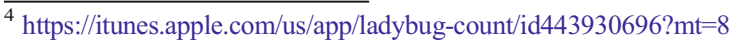

5 https://itunes.apple.com/en/app/fingu/id449815506? $\mathrm{mt}=8$
} 
Fig. 1 View of the LBC screen with a player that set three fingers on the screen

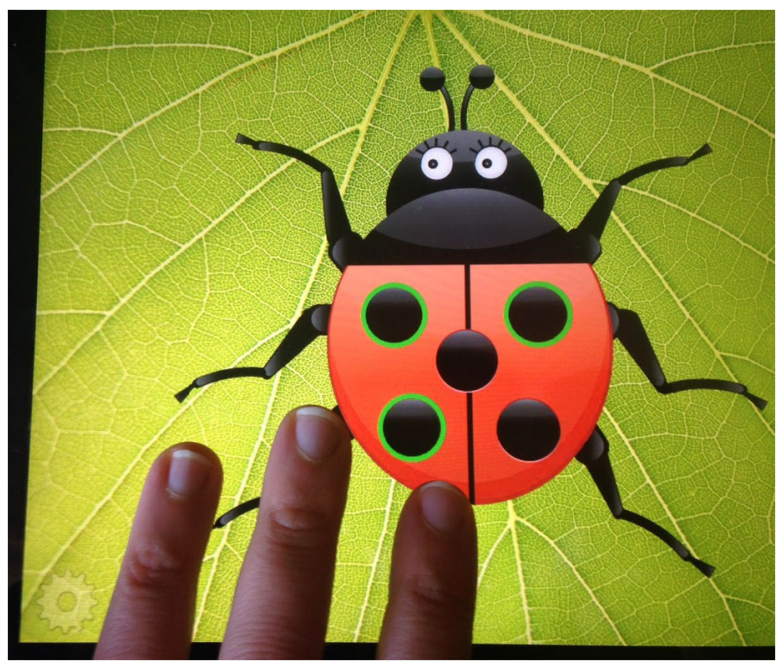

\section{Results}

In general only a few children exhibited performances without mistakes in LBC, and all children found $\mathrm{F}$ to be challenging. No child, however, was ever discouraged and wanted to leave her group: frequently weaker children were helped by classmates who proposed strategies and solutions verbally, without ever touching the iPad (this was an explicit rule enforced by the researchers).

Fig. 2 a View of the screen of $F$ with two groups of floating fruits in fixed arrangements, and $\mathbf{b}$ view of the screen of $\mathrm{F}$ after the player has set five fingers on the screen, simultaneously
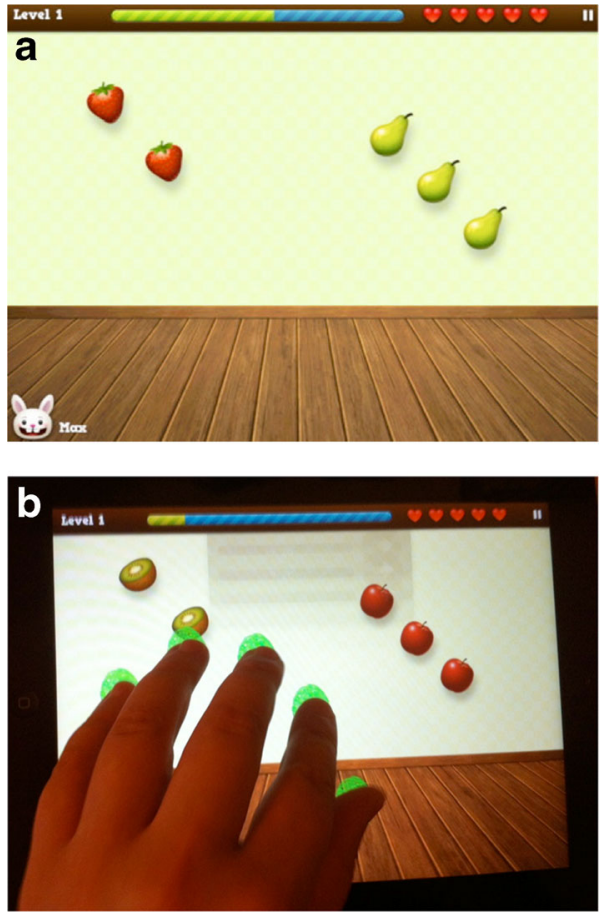
The video recordings show different strategies that the children seemed to adopt for playing with $\mathrm{LBC}$ and $\mathrm{F}$.

We present recurring strategies that appeared during the children's interactions with LBC and F.

\section{Children's Strategies Emerging from the Interaction with LBC}

While the general aim of children's action was always the same, the differences in the numbers of dots on the back of the ladybug seemed to generate different situations for the children, which could correspond to different specific strategies. In fact, as we will show, while some children developed general strategies others developed strategies that were sensitive to the number of dots to "count".

Furthermore, even if we could in principle distinguish between more and less efficient strategies, the link between efficient/not-efficient strategies and success/ failure is not a straightforward one. In fact, on the one hand, due to the fact that LBC is not timed and allows children to carry out as many trials as they want, even those strategies which we might recognize as "not-efficient", in the end led children to success. On the other hand, children could fail to enact properly "efficient" strategies, because, for instance, they would fail to properly touch the screen, thus not giving the desired input, or fail to correctly count up dots or fingers.

\section{Children's General Strategies in LBC}

We start by describing the general strategies enacted by children, that is the strategies whose enactment is not apparently linked to a "small" or "large" number of dots on the ladybug's back.

- A common strategy consisted in exploiting the symmetry of arrangement of the dots on the ladybug's back. In fact, the back is divided in two halves and the dots are always arranged symmetrically upon it: when the number of dots is even, they are arranged symmetrically on the 2 halves of the back of the ladybug; when the number of dots is odd, 1 or 3 dots are arranged along the wing line, in the center of the ladybug's back, and the remaining ones are arranged symmetrically on the 2 wings. Children who developed this strategy, seemed to recognize the symmetry of the configuration of the dots and placed their fingers on the screen, reproducing the same arrangement (general-arrangement, abbreviated g-arr) with their hands. This strategy was enacted mainly with even numbers of dots, but two children also repeatedly attempted to use it with an odd number of dots.

- Another strategy (general-bunches, abbreviated g-bun) sees children placing fingers on the screen in small bunches at first ( 2 or 3 at a time) and then one at the time to reach the appropriate numerosity. Children do not explicitly count the dots, but seem to estimate that there are more than few.

- The previous strategies, and other ones we will describe later, do not involve children's explicit verbal counting. In some cases, seemingly, after recognizing the small number of dots (see the following $s 1$-seq and s1-sim) or the special arrangement ( $g$-arr), the children could give directly the correct input on the screen. But when the number of dots increased or special configurations were not 
perceived, such automatism did not seem to occur: children relied on verbal counting to manage the represented numerosity. In these cases children verbally counted the dots on the ladybug's back (pointing at them one-by-one with an index finger) and then counted their fingers (lifting them one-by-one sequentially), and placed the fingers raised, simultaneously, on the screen (general-counting-simultaneously, abbreviated g-count-sim).

- A different strategy relying on explicit counting consisted in verbally counting the dots on the ladybug's back and in placing one finger at the time on the screen as s/ he says the number-words (general-counting-sequentially, abbreviated g-countseq).

- Another strategy which involved counting, but which cannot function (unless the number of dots is equal to 1) is an attempt to count the dots one at the time and then try to tap the screen with the same finger or different fingers that number of times, but without leaving the fingers on the screen (generalcounting-lifting, abbreviated g-count-lift). Even if this is a failing strategy, some children made several unsuccessful attempts before discarding it and trying something different. That is a paradigmatic example testifying general resistance of children's own strategies.

- Finally, in few cases, children attempted strategies in which they would place their fingers either simultaneously or sequentially in an apparently "random" way. By writing "random" we do not mean that children place their fingers in a way which is random from their perspective, but in which we, as observers, could not recognize any clear relation between children's actions and the number of dots displayed, or any intention of the child to place on the screen a number of fingers equal to the number of dots.

\section{Children's Specific Strategies in LBC}

We now describe the strategies that were sensitive to the number of dots to "count".

The first class of specific situations is characterized by the presence of a very small number of dots: 1 to 3 .

- The most common strategy (specific-small-quantities-simultaneously, abbreviated s1-sim) enacted in this class of situations seems to involve the rapid recognition of small numerosities by children through subitizing. In fact, children who used this strategy seemed to perceive the number of dots and place the same number of fingers on the screen simultaneously. The fingers were placed randomly on the screen. This strategy was not accompanied by verbal utterances. Though seemingly quite trivial to be enacted, the strategy requires the development of the crucial component abilities and it can be related to several of Gelman and Gallistel's principles (1978) as we will show in Table 2; in fact, it can be seen as the bodily enactment of these principles.

- Another strategy (specific-small-quantities-sequentially, abbreviated s1-seq) consisted of placing fingers on the screen sequentially starting from one finger until the ladybug left the leaf. With respect to the former, this strategy did not need the child to either initially recognize the exact number of dots or reach a 
sophisticated mental representation of his/her fingers. In this sense the enactment of the strategy might suggest a less mature development of the child's number-sense. However without a deeper analysis we advocate much caution before drawing this kind of conclusion.

The second class of situations is characterized by the presence of a high number of dots: 7 to 10 . In several cases the children reacted to the appearance of the ladybug with a high number of dots through verbal expressions such as: "How many!" "That's a lot!". This allowed us to infer that the situations were different for them.

- One of the strategies (specific-large-quantities-sequentially, abbreviated s2$s e q$ ) enacted to face this class of situations was analogous to 1 -seq: the child placed his/her fingers on the screen sequentially starting from one finger until the ladybug left the leaf. S2-seq and $s 1-s e q$ can be considered from the adult's point of view as the same strategy because in principle they do not seem to depend on any anticipation of the numerosity of the dots, and indeed we have given nearly the same description for both. However they were not the same strategy for the children. In fact only one child used both; one child used s1seq with small numerosities and other strategies with larger numerosities, and five children used $s 2$-seq with large numerosities but other strategies with smaller numerosities.

- A further strategy (specific-large-quantities-forwards, abbreviated s2-for) can be described as follows: the child recognized "many" dots and started placing all the fingers of one hand, to then adjust the number by placing other fingers sequentially until the ladybug walked away. This strategy does not necessarily involve counting the actual number of dots, but estimating that it is greater than five. Besides other principles already mentioned, this strategy sees, in a sense, the bodily counterpart of a sort of sophisticated "counting-on" principle, though less sophisticated than one in which the number labels are also pronounced verbally.

- However the most common strategy in this class of situations (specific-largequantities-backwards, abbreviated s2-back) saw the child placing all his/her fingers on the screen and then possibly removing fingers one at time until the ladybug left the leaf. This strategy starts with the recognition of the situation of there being "many" dots on the screen. Its enactment can be considered a sort of bodily counterpart of the of "counting backwards" principle. However, as noted above, to only enact this with the hands can be considered much less sophisticated than also pronouncing the number labels verbally.

\section{Children's Strategies in LBC and Aspects of Number-Sense}

The above description should highlight the fact that the different strategies can be related to the different aspects of number-sense which we have set out to explore. Table 2 below shows more clearly the relationship which can be established between children's strategies and these aspects of number-sense. 


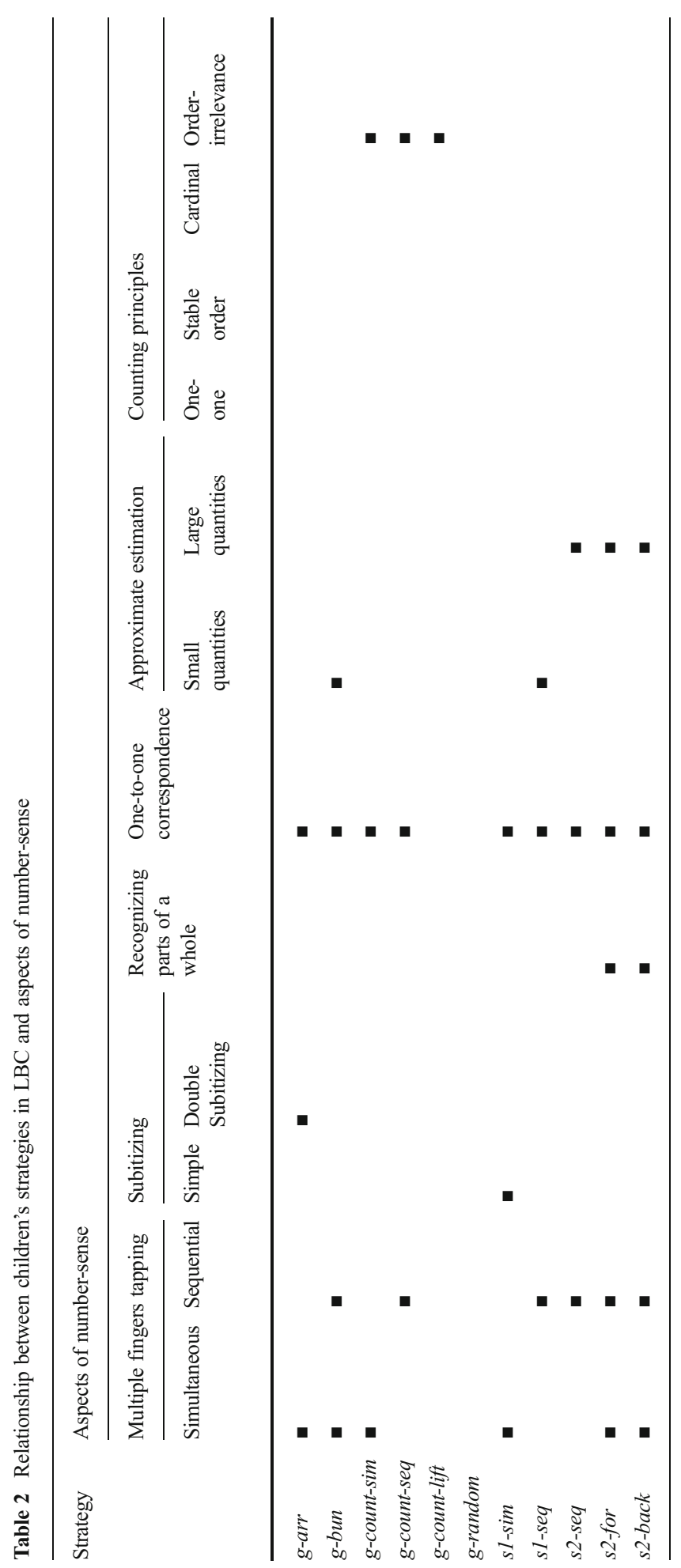




\section{Children's Strategies Emerging from the Interaction With F}

A priori it could seem reasonable to distinguish situations in $\mathrm{F}$ on the basis of the number of floating objects displayed or on the number of the groups of floating objects, and to foresee that children use different strategies accordingly. Indeed the analysis of videos showed that children elaborated strategies which they used regularly in every situation: the first strategy which was successful in a few cases, became the dominant one despite possible successive failures.

To select the exact number of fingers and place them simultaneously on the screen within a limited amount of time was a source of difficulties for most children: it requires the development of advanced fine motor abilities. Also for this reason, we think, children tended to stick with the first strategy which appeared to be effective even if it worked only in very few initial cases. It is worthwhile noticing that due to the difficulties mentioned above, some children obtained positive (or negative) feedback from the system even trying and placing (not properly) the wrong (right) number of fingers on the screen.

- Children recognized the number of objects (be they in a single group or in two ones) without verbally counting and tried to place on the screen the corresponding number of fingers either of a same hand (1-hand-simultaneously, abbreviated $1 \mathrm{~h}$ sim) or of two hands (2-hands-simultaneously, abbreviated $2 \mathrm{hs}$-sim) simultaneously. As mentioned above, whether the children used one or two hands did not depend on the number of groups of floating objects. In many cases children tried to place their fingers as close as possible to the floating objects, so as to "catch" them, or to reproduce with their finger the same spatial arrangement of the floating objects.

- Some children, after recognizing (and saying explicitly) or counting up the fruits, tried to place their fingers sequentially, not fast enough for the software to recognize all the touches (sequentially, abbreviated seq). In this case they obtained negative feedback. Nevertheless, children enacted this strategy repeatedly, also for higher numbers of objects, before abandoning it.

- While the strategies described above entail the children's immediate recognition of the number of objects, or at least the clear effort by children of recognizing the number of objects, a few children enacted strategies which did not pass through the recognition of numerosities. These children placed a bunch of fingers of a same hand (1-hand-catch, abbreviated 1 h-catch) or of two hands (2-hands-catch, abbreviated 2 hs-catch) on the screen around the floating objects to try to "catch" them, without any apparent attention to their numerosity. Once again children used one or two hands regardless the number of groups of floating objects.

- Finally, a few children quickly counted the floating objects and then placed their fingers on the screen simultaneously (counting, abbreviated count). Even if in principle this strategy is highly effective, it did not always lead to success: pressed by the time constraints some children failed to count correctly or to place their fingers properly on the screen.

For the sake of clarity, we tried to distinguish the various strategies as clearly as possible, and even if it is true that most children tended to keep enacting the same strategy, nevertheless in some cases the interactions would have to be described in a 
less clear-cut way than the above description may suggest. That is the case, for instance, with Andrea. Andrea's most used strategy is $2 \mathrm{hs}$-sim; but when he was pressed by his classmates sitting next to him shouting "hurry up!", he would start raising his fingers and trying to form the right number using both hands, but then he ended up dropping his hands, as if he were trying to catch the objects regardless of their number (as in $2 h s$ catch strategy). We interpret behaviors like this as being representative of a cognitive conflict going on between at least two different strategies: the seemingly spontaneous and intuitive $2 \mathrm{hs}$-catch (since there are frequently two bunches of fruits floating) and (at least one of) the two strategies $2 h s$-sim or count, possibly constructed products of the child's cultural exposure to counting and analogical number recognition and representation practices. In fact, it might be the case that an inhibitory control needs to be exercised over the more intuitive catching strategies in order to carry out a strategy correctly related to numerosity. Such inhibitory control may dissolve when too many conflicting and/or time-pressing stimuli concur.

\section{Children's Strategies in F and Aspects of Number-Sense}

Even if $\mathrm{F}$ inhibits, intentionally or not, some strategies which can be related to the development of some aspects of number-sense (for instance, counting or sequential finger tapping), and it triggers the development of fewer strategies than LBC, nevertheless many of the strategies developed by children can be still related to important aspects of number-sense, as shown in Table 3.

\section{Synthesis and Conclusions}

The analyses presented in the previous sections highlight the stable recurring strategies which children developed and enacted while interacting with two apps that exploit the multitouch potential through a variety of different situations. The classifications of strategies presented were mostly based on the way the children's fingers touched the screen and not on possible ways in which they might have obtained information from the screen; a different perspective could of course lead to different classifications. Anyway, as argued, the stability and regularity of these strategies suggest that they can be related to operational invariants of schemes which children are developing, that is to the implicit knowledge which structures and drives the behavior of young children when they interact with these apps.

A crucial component of these strategies, and of the underlying implicit knowledge at stake, consists in children's particular uses of their fingers and, specifically, in their ability to use fingers to represent numbers in an analogical format, an ability considered crucial in the development of number-sense. Our analyses point out possible links between the observed strategies and important aspects of number-sense, as acknowledged in the fields of mathematics education, cognitive and developmental psychology and neuroscience. These are: subitizing, approximate estimation of quantities, fine-motor ability, establishing one-to-one correspondence between fingers and objects (possibly independently of numbers), recognizing parts of a whole, mastering basic and sophisticated counting principles. 


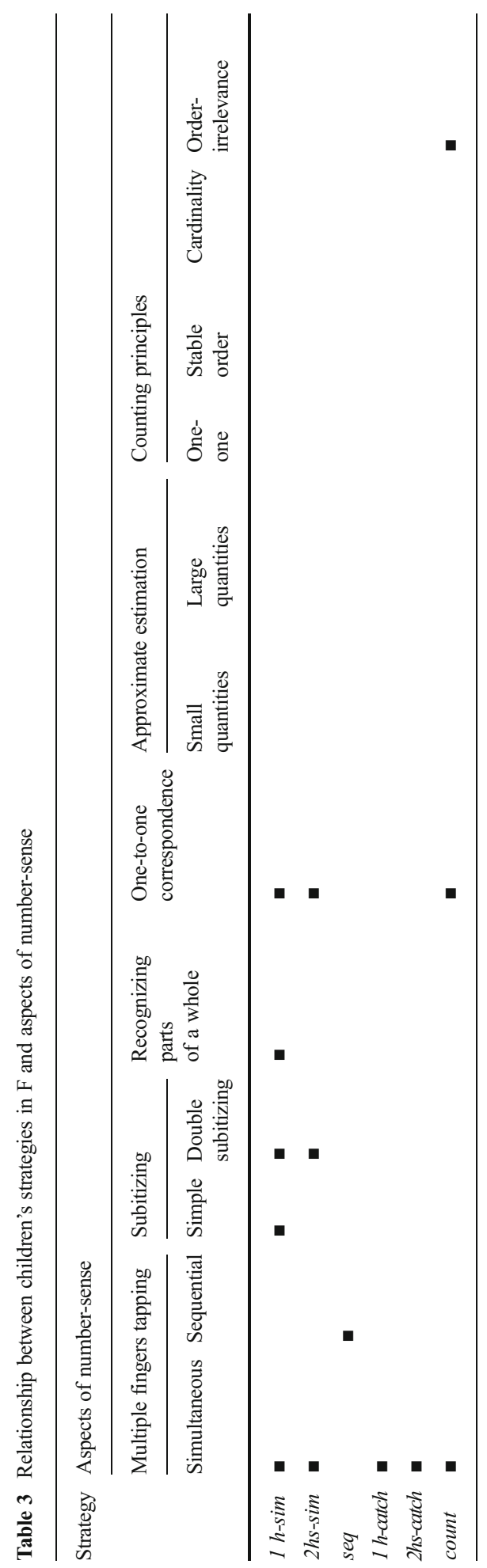


Our findings and their discussion confirm the hypothesis that multi-touch technology has the potential to foster important aspects of children's development of numbersense.

It is worthwhile noticing that the apps used in the sequence of activities have different characteristics which foster the development of various aspects of numbersense. For instance LBC may encourage the use of strategies based on explicit counting, or on a first approximate estimation of quantities followed by successive adjustments. On the contrary, F, being timed and requiring simultaneous finger touches, inhibits explicit counting and successive adjustments, it seems to be more functional to the development of strategies triggering the representation of numbers with fingers and the ability to subitize (possibly two small quantities simultaneously). In a sense, we could say that the two apps have the potential of playing complementary roles in the development of children's number-sense. However a more thorough analysis reveals that the different strategies, which can be developed interacting with each app alone, promote the development of different aspects of number-sense. An interesting and unexpected finding was that $\mathrm{F}$ also seems to have the potential of fostering inhibitory control over a spontaneous urge of "capturing" the floating fruits. This may be of particular interest to some researchers because of the new recent hypotheses advanced about the cognitive roots of dyscalculia, which seem to be visual-spatial memory and inhibitory control (Szucs et al. 2013).

These considerations have important consequences from an educational point of view. If an educator's intention is that of promoting the development of number-sense (or at least of its aspects considered here), and decides to use apps similar to the ones illustrated here, s/he will have to explicitly promote the elaboration and enactment of different strategies by the same child. In fact, as we pointed out, children tend to rely on very few (possibly just one) strategies and using a variety of different strategies does not appear to be a spontaneous process for them. Neither does it seem spontaneous for children to reflect on their own strategies, to question them, to wonder why they work or fail, to relate them to other children's strategies. This is of crucial importance if we consider the finding that children can fail to properly enact "efficient" strategies; for instance, failing to touch the screen properly, thus not giving the desired input, or receiving positive feedback sometimes even when enacting a "non-efficient" strategy. Thus emerges the need of an explicit well-designed didactical intervention of the teacher to orchestrate a more complete learning process.

Along these lines we note that there are other apps that seemingly withhold a multitouch potential with respect to developing number-sense similar to the ones analyzed. Moreover, there are other apps that propose different types of multitouch interactions, for example with animated virtual manipulatives, and that therefore may exploit the multitouch potential in different ways.

Overall, we hope to have contributed to shedding light onto some of the new frontiers that multi-touch technology has opened in educational terms. We hope that our framework and consequent analyses will be useful at two levels: 1) for helping recognize apps for young children with high multi-touch potential with respect to the development of number-sense; 2) as a tool of analysis for observing the development of number-sense in young children through their interactions with similar apps.

Taking another step back to see a broader picture, through this study we have addressed the issue of children's development of number-sense, capitalizing on recent 
advances developmental and cognitive psychology, and neuroscience. No need to say that mathematics education and these disciplines address different research problems, from different perspectives, and they rely on different scientific paradigms; so communication between them is not always easy. Notwithstanding, we think that in many cases, as in this one, there is the possibility of identifying boundary objects, lying at intersecting areas between these research fields, that have the potential of triggering fruitful interactions and even collaborations between them. In order for this collaboration to actually become fruitful more research at the crossroads is necessary.

Acknowledgments We are deeply endowed to M.G. Bartolini Bussi for having pointed us in this direction of research. Moreover, we wish to thank the pre-service teacher Giorgia Giacopini for carrying out and documenting the interventions. Finally, we wish to thank the children of Modena who participated to the activities so enthusiastically.

\section{References}

Abrahamson, D. \& Howison, M. (2010). Embodied artifacts: Coordinated action as an object-to-think-with. In D. L. Holton (Ed) Embodied and enactive approaches to instruction: Implications and innovations. AERA 2010, Denver, May 3, 2010.

Andres, M., Seron, X., \& Oliver, E. (2007). Contribution of hand motor circuits to counting. Journal of Cognitive Neuroscience, 19, 563-576.

Arzarello, F., Pezzi, G., \& Robutti, O. (2007). Modelling body motion: an approach to functions using measuring instruments. In W. Blum, et al. (eds), Modelling and Applications in Mathematics Education: the 14th ICMI Study (chap 3.1.1 129-136) Springer: New York.

Barendregt, W., Lindstrom, B., Rietz-Leppanen, E., Holgersson, I., \& Ottosson, T. (2012). Development and evaluation of Fingu: A mathematics iPad game using multi-touch interaction. IDC 2012, June 12-15, 2012, Bremen, Germany, 1-4.

Berch, D. B. (2005). Making sense of number sense: implications for children with mathematical disabilities. Journal of Learning Disabilities, 38(4), 333-339.

Bourmaud, G. (2006). Les systemes d'instruments: methodes d'analyse et perspectives de conception. Thèse de Doctorat de Psychologie Ergonomique, Université Paris 8.

Brissiaud, R. (1992). A toll for number construction: Finger symbol sets. In J. Bidaud, C. Meljac, \& J.-P. Fischer (Eds.), Pathways to number. Children's developing numerical abilities. New Jersey: Lawrence Erlbaum Associates.

Butterworth, B. (1999). What counts - how every brain is hardwired for math. New York: The Free Press.

Butterworth, B. (2005). The development of arithmetical abilities. Journal of Child Psychology and Psychiatry, 46, 3-18.

Charoenying, T., Gaysinsky, A., \& Riyokai, K. (2012). The choreography of conceptual development in computer supported instructional environments. In Proceedings of IDC 2012, June 12-15, 2012, Bremen, Germany, 162-167.

Clements, D. H., \& Sarama, J. (2007). Effects of a preschool mathematics curriculum: summary research on the building blocks project. Journal for Research in Mathematics Education, 38, 136-163.

Cobb, P., McClain, K., de Silva Lamberg, T., \& Dean, C. (2003). Situating teachers' instructional practices in the institutional setting of the school and district. Educational Researcher, 32(6), 13-24.

de Freitas, E., \& Sinclair, N. (2013). New materialist ontologies in mathematics education: the body in/of mathematics. Educational Studies in Mathematics, 83(3), 453-470. doi:10.1007/s10649-012-9465-z.

Dehaene, S. (2001). Subtracting pigeons: logarithmic or linear? Psychological Science, 12, 244-246.

Domahs, F., Kaufmann, L. \& Fischer, M.H. (2012). Handy numbers: Finger counting and numerical cognition. Frontiers Research Topic Ebook. Retrieved from: http://www.frontiersin.org/books/Handy numbers_Finger_counting_and_numerical_cognition/98.

English, L., \& Mulligan, J. (2013). Reconceptualizing early mathematics learning. Dordrecht: Springer Science-Business Media. 
Gallese, V., \& Lakoff, G. (2005). The brain's concepts: the role of the sensory-motor system in conceptual knowledge. Cognitive Neuropsychology, 22(3-4), 455-479.

Gelman, R., \& Gallistel, C. R. (1978). The child's understanding of number. Cambridge: Harvard University Press.

Goldin-Meadow, S. (2004). Gesture's role in the learning process. Theory Into Practice, 43(4), 314-321.

Gracia-Bafalluy, M. G., \& Noël, M. P. (2008). Does finger training increase young children's numerical performance? Cortex, 44, 368-375.

Griffin, S. A., Case, R., \& Siegler, R. S. (1994). Rightstart: Providing the central conceptual prerequisites for first formal learning of arithmetic to students at risk for school failure. In K. McGilly (Ed.), Classroom lessons: Integrating cognitive theory and classroom practice (pp. 24 49). Cambridge: MIT Press.

Healy, L., \& Kynigos, K. (2009). Charting the microworld territory over time: design and construction in mathematics education. $Z D M, 42,63-76$.

Ladel, S. and Kortenkamp, U. (2009). Realisations of MERS (multiple extern representations) and MELRS (multiple equivalent linked representations) in elementary mathematics software. In V. Durand-Guerrier, S. Soury-Lavergne, and F. Arzarello, (Eds.), Proceedings of the Sixth Congress of the European Society for Research in Mathematics Education. Lyon (France).

Ladel, S. \& Kortenkamp, U. (2011). Implementation of a multi-touch-environment supporting finger symbol sets. In Proceedings of the Seventh Congress of the European Society for Research in Mathematics Education. Rzeszow, Poland.

Lafay, A., Thevenot, C., Castel, C., \& Fayol, M. (2013). The role of fingers in number processing in young children. Frontiers in Psychology, 4, 488. doi:10.3389/fpsyg.2013.00488.

Lagrange, J.-B. (1999). Complex calculators in the classroom: theoretical and practical reflections on teaching pre-calculus. International Journal of Computers for Mathematical Learning, 4(1), 51-81.

Margolinas, C., \& Wosniak, F. (2012). Le nombre à l'école maternelle. Une approche didactique. Bruxelles: De Boeck.

Mulligan, J. (2011). Towards understanding the origins of children's difficulties in mathematics learning. Australian Journal of Learning Difficulties, 16(1), 19-39. doi:10.1080/19404158.2011.563476.

Mulligan, J. T., \& Mitchelmore, M. C. (2013). Early awareness of mathematical pattern and structure. In L. English \& J. Mulligan (Eds.), Reconceptualizing early mathematics learning (pp. 29-46). Dordrecht: Springer Science-Business Media.

National Council of Teachers of Mathematics, (2000). Principles and standards for school mathematics. Reston: NCTM.

Nemirovsky, R. (2003). Three conjectures concerning the relationship between body activity and understanding mathematics. In: N.A. Pateman, B.J. Dougherty \& J.T. Zilliox (Eds.), Proc. 27th Conf. of the Int. Group for the Psychology of Mathematics Education (Vol 1, pp.103-135). Honolulu, USA: PME.

Nemirovsky, R., \& Ferrara, F. (2009). Mathematical imagination and embodied cognition. Educational Studies in Mathematics, 70(2), 159-174.

Noël, M. P. (2005). Finger gnosia: a predictor of numerical abilities in children? Child Neuropsychology, 11, $1-18$.

Nunez, R. E. (2011). No innate number line in the human brain. Journal of Cross-Cultural Psychology, 42(4), 651-668. doi:10.1177/0022022111406097.

Papert, S. (1980). Mindstorms: Children, computers and powerful ideas. New York: Basic Books.

Penner-Wilger, M., Fast, L., LeFevre, J.A., Smith-Chant, B.L, Skwarchuk, S.L, Kamawar, D., \& Bisanz, J. (2007). The Foundations of Numeracy: Subitizing, Finger Gnosia, and Fine Motor Ability. In D. S. McNamara \& J. G. Trafton (Eds.), Proceedings of the 29th annual conference of the cognitive science society. Austin, TX: Cognitive Science Society. pp. 1385-1390.

Perry, B., \& Dockett, S. (2013). Reflecting on young Children's mathematics learning. In L. English \& J. Mulligan (Eds.), Reconceptualizing early mathematics learning (pp. 149-162). Dordrecht: Springer Science-Business Media.

Radford, L. (2014). Towards an embodied, cultural, and material conception of mathematics cognition. ZDM, 46(3), 349-361.

Radford, L., Bardini, C., Sabena, C., Diallo, P., \& Simbagoye, A. (2005). On embodiment, artifacts, and signs: A semiotic - cultural perspective on mathematical thinking. In H. L. Chick \& J. L. Vincent (Eds.), Proceedings of the 29th International Group for the Psychology of Mathematics Education (vol. 4, 113 122). Melbourne, Australia: PME.

Resnick, L. B., Bill, V., Lesgold, S., \& Leer, M. (1991). Thinking in arithmetic class. In B. Means, C. Chelemer, \& M. S. Knapp (Eds.), Teaching advanced skills to at-risk students: Views from research and practice (pp. 27-53). San Francisco: Jossey-Bass. 
Sato, M., Cattaneo, L., Rizzolatti, G., \& Gallese, V. (2007). Numbers within our hands: modulation of corticospinal excitability of hand muscles during numerical judgment. Journal of Cognitive Neuroscience, 19(4), 684-93.

Sedig, K., \& Sumner, M. (2006). Characterizing interaction with visual mathematical representations. International Journal of Computers for Mathematical Learning, 11(1), 1-55.

Sinclair, N. \& Baccaglini-Frank, A. (2015). Digital technologies in the early primary school classroom. Chapter to appear in L. English (Ed.), Handbook of International Research in Mathematics Education. Taylor and Francis.

Sinclair, N., \& Jackiw, N. (2011). Touchcounts [computer software]. Tangible mathematics project, Simon Fraser University.

Sinclair, N., \& Moss, J. (2012). The more it changes, the more it becomes the same: the development of the routine of shape identification in dynamic geometry environments. International Journal of Education Research, 51\&52, 28-44.

Slavit, D. (1998). The role of operation sense in transitions from arithmetic to algebraic thought. Educational Studies in Mathematics, 37, 251-274.

Sophian, C., \& McCorgray, P. (2009). Part-whole knowledge and early arithmetic problem solving. Cognition and Instruction, 12(1), 3-33.

Sowder, J. (1992). Estimation and number sense. In D. A. Grouws (Ed.), Handbook of research on mathematics teaching and learning (pp. 371-389). New York: Macmillan.

Star, S. L., \& Griesemer, J. R. (1989). Institutional ecology, "translations" and boundary objects: amateurs and professionals in Berkley's museum of vertebrate zoology, 1907-1939. Social Studies of Science, 19, 387420 .

Szucs, D., Devine, A., Soltesz, F., Nobes, A., \& Gabriel, F. (2013). Developmental dyscalculia is related to visuo-spatial memoryand inhibition impairment. Cortex, 49(10), 2674-2688. doi:10.1016/j.cortex.2013. 06.007.

Thompson, J. C., Abbott, D. F., Wheaton, K. J., Syngeniotis, A., \& Puce, A. (2004). Digit representation is more than just hand waving. Cognitive Brain Research, 21, 412-17.

Vergnaud, G. (1990). La théorie des champs conceptuels. Recherches en Didactique des Mathématiques, 10, $133-170$.

Vergnaud, G. (2005). Repères pour une théorie psychologique de la connaissance. In A. Marcier \& C. Margolinas (eds), Balises pour la didactiques desmathématiques (123-136). La Pensée Sauvage Editions.

Vergnaud, G. (2009). The theory of conceptual fields. Human Development, 52(2), 83-94.

Zanarelli, C. (2003) Caractérisation des stratégies instrumentales de gestion d'environnements dynamiques: Analyse de l'activité de régualtion du métro. Thèse de Doctorat de Psychologie Ergonomique, Université Paris 8.

Zorzi, M., Priftis, K., \& Umiltà, C. (2002). Neglect disrupts the mental number line. Nature, 417, 138-139. 